\title{
The Danish Registry of Diabetic Retinopathy
}

This article was published in the following Dove Press journal:

Clinical Epidemiology

25 October 2016

Number of times this article has been viewed

\author{
Nis Andersen ${ }^{1,2}$ \\ Jesper $\emptyset$ stergaard \\ Hjortdal ${ }^{1,3}$ \\ Katja Christina Schielke ${ }^{4}$ \\ Toke Bek ${ }^{3}$ \\ Jakob Grauslund ${ }^{5}$ \\ Caroline Schmidt Laugesen ${ }^{6}$ \\ Henrik Lund-Andersen ${ }^{7}$ \\ Charlotte Cerqueira ${ }^{8}$ \\ Jens Andresen ${ }^{2}$ \\ 'Danish Ophthalmological Society, \\ Copenhagen, ${ }^{2}$ Organization of \\ Danish Ophthalmologists in Private \\ Practice, Copenhagen, ${ }^{3}$ Department \\ of Ophthalmology, Aarhus University \\ Hospital, Aarhus, ${ }^{4}$ Department of \\ Ophthalmology, Aalborg University \\ Hospital, Aalborg, ${ }^{5}$ Department of \\ Ophthalmology, Odense University \\ Hospital, Odense, ${ }^{6}$ Department \\ of Ophthalmology, Copenhagen \\ University Hospital Roskilde, Roskilde, \\ ${ }^{7}$ Department of Ophthalmology, \\ Glostrup Hospital, ${ }^{8}$ Registry Support \\ Centre (East) - Epidemiology and \\ Biostatistics, Research Centre for \\ Prevention and Health, \\ Rigshospitalet - Glostrup, University \\ of Copenhagen, Copenhagen, \\ Denmark
}

Aim of database: To monitor the development of diabetic eye disease in Denmark and to evaluate the accessibility and effectiveness of diabetic eye screening programs with focus on interregional variations.

Target population: The target population includes all patients diagnosed with diabetes. Denmark (5.5 million inhabitants) has $\sim 320,000$ diabetes patients with an annual increase of 27,000 newly diagnosed patients. The Danish Registry of Diabetic Retinopathy (DiaBase) collects data on all diabetes patients aged $\geq 18$ years who attend screening for diabetic eye disease in hospital eye departments and in private ophthalmological practice. In 2014-2015, DiaBase included data collected from 77,968 diabetes patients.

Main variables: The main variables provide data for calculation of performance indicators to monitor the quality of diabetic eye screening and development of diabetic retinopathy. Data with respect to age, sex, best corrected visual acuity, screening frequency, grading of diabetic retinopathy and maculopathy at each visit, progression/regression of diabetic eye disease, and prevalence of blindness were obtained. Data analysis from DiaBase's latest annual report (2014-2015) indicates that the prevalence of no diabetic retinopathy, nonproliferative diabetic retinopathy, and proliferative diabetic retinopathy is $78 \%, 18 \%$, and $4 \%$, respectively. The percentage of patients without diabetic maculopathy is $97 \%$. The proportion of patients with regression of diabetic retinopathy $(20 \%)$ is greater than the proportion of patients with progression of diabetic retinopathy $(10 \%)$. Conclusion: The collection of data from diabetic eye screening is still expanding in Denmark. Analysis of the data collected during the period 2014-2015 reveals an overall decrease of diabetic retinopathy compared to the previous year, although the number of patients newly diagnosed with diabetes has been increasing in Denmark. DiaBase is a useful tool to observe the quality of screening, prevalence, and progression/regression of diabetic eye disease.

Keywords: diabetes, DiaBase, Danish Diabetes Database, national annual report, quality of care, database, registry, quality indicator

\section{Introduction}

Diabetic retinopathy is the most common complication in diabetes. ${ }^{1,2}$ It is a chronic, progressive, potentially sight-threatening disease of the retinal microvasculature that is associated with prolonged hyperglycemia and other conditions linked to diabetes mellitus such as hypertension. ${ }^{3}$ The threat to sight is due to either growth of new vessels leading to intraocular hemorrhage and possible retinal detachment with profound sight loss or localized damage to the macula of the eye with loss of central visual acuity. ${ }^{3}$
Correspondence: Nis Andersen Amagerbro Øjenklinik, Amagerbrogade 62, 2300 København, Denmark Tel +4532956129 Email nis_andersen@yahoo.dk
Clinical Epidemiology 2016:8 613-619 (Thematic series on clinical quality databases in Denmark) 6 I 3 (c) (1) (5) 2016 Andersen et al. This work is published and licensed by Dove Medical Press Limited. The full terms of this license are available at https://www.dovepress.com/terms.

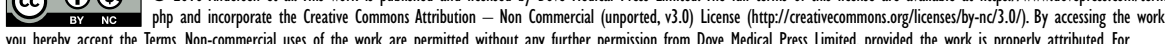
you hereby accept the Terms. Non-commercial uses of the work are permitted without any further permission from Dove Medical Press
permission for commercial use of this work, please see paragraphs 4.2 and 5 of our Terms (https://www.dovepress.com/terms.php). 
Grading of diabetic retinopathy is based on visible signs of increasing severity on ophthalmoscopy and on imaging. Diabetic retinopathy is classified as proliferative or nonproliferative (background/preproliferative) retinopathy based on the presence or absence of abnormal new vessels, respectively.

Subgroups of nonproliferative diabetic retinopathy (mild, moderate, preproliferative) reflect increasing severity of the disease, which consequently results in shortening of screening intervals. ${ }^{4}$ Nonproliferative diabetic retinopathy is typically managed by optimizing the patient's general health. Treatment of proliferative diabetic retinopathy comprises panretinal photocoagulation. It is hypothesized that this technique reduces the amount of ischemic retina, and thus the production of angiogenic molecules.

Retinopathy affecting the macula is separately described as diabetic maculopathy. Diabetic maculopathy is a leading cause of visual loss in diabetic retinopathy. It usually affects older, noninsulin-dependent diabetes patients. Diabetic maculopathy is divided into three types, based on whether it causes focal, ischemic or diffuse edema, and may include tractional (vitreoretinal) or nontractional (intraretinal) components. $^{3}$ The management of diabetic macular edema has advanced significantly with the introduction of anti-VEGF (vascular endothelial growth factor) treatments. ${ }^{3}$ However, macular laser treatment still plays a major role in treating noncenter-involving macular edema. ${ }^{5}$

Vision loss due to diabetic retinopathy is one of the leading causes of visual loss worldwide and is an important cause of impaired vision and disability in the working-age population. ${ }^{6,78}$ Advanced diabetic eye disease has a negative influence on quality of life. ${ }^{6}$ Therefore, eye screening for the diabetes population aims to identify patients with early signs of sight-threatening disease to facilitate efficient treatment and prevent loss of sight.

\section{Aim of database}

The Danish Registry of Diabetic Retinopathy (DiaBase) was established to monitor the development of diabetic eye disease in Denmark and to evaluate the accessibility and effectiveness of diabetic eye screening programs with focus on interregional variations. ${ }^{9}$ The main aim of the registry is to enable evaluation of quality of care for patients with diabetic eye disease.

\section{Target population}

The target population includes all patients diagnosed with diabetes in Denmark. At present, Denmark (5.5 million inhabitants) has $\sim 320,000$ diabetes patients with an annual increase of $\sim 27,000$ newly diagnosed patients. ${ }^{10}$ The prevalence of diabetes in Denmark has more than doubled since 1996 and was 5737 per 100,000 people in $2012 .{ }^{10}$ DiaBase contains data on all diabetes patients aged $\geq 18$ years who attend screening for diabetic eye disease in the five regions of Denmark. Eye examination of children with diabetes is recorded in the Children Diabetes Registry (DanDiabKids [children and teenagers with diabetes $<18$ years old]). In 2011, the Adult Diabetes Registry (adult patients with diabetes from 18 years old), the DiaBase, and the DanDiabKids joined to form the Danish Diabetes Database. ${ }^{9}$

DiaBase receives data collected from hospital eye departments and private ophthalmological practices where diabetes patients aged $\geq 18$ years attend diabetic eye screening. In Denmark, diabetes care is managed by both primary care physicians in private practice and hospital-based endocrinologists. Diabetic eye screening for most patients attending their primary care physician is delivered by an ophthalmologist in private practice. Patients being followed in endocrinology departments receive diabetic eye screening in the eye department of the respective hospital. Data from each screening visit are collected and sent electronically to DiaBase. An annual report analyzing diabetes screening data from the previous year is issued every spring by the steering committee. National guidelines, based on international guidelines, 3,5 determine screening intervals and treatment protocols.

DiaBase was established between 2003 and 2006 and is still in the development process. The systematic collection of outpatient data from hospitals in Denmark started in 2007 and was extended nationwide in 2010. Data collection on patients screened by ophthalmologists in private practice started in 2013. In 2014-2015, the Registry included data from 77,968 diabetes patients; ${ }^{11}$ of these patients, 57,985 had been screened by ophthalmologists in private practice, whereas 20,291 patients had been screened in hospitals. ${ }^{11}$

\section{Main variables}

Key quality indicators for DiaBase were selected according to international standards for good clinical practice: two process indicators to examine efficiency and three performance indicators to examine outcome 9 (Table 1). Indicator measurements are based on the collection of data with regard to the following main variables: ${ }^{9}$

- Registering screening unit

- Patient name and unique Danish identification number

- Date of screening visit

- Indication for screening 
Table I Indicators and standards for DiaBase

\begin{tabular}{ll}
\hline Area & Indicator \\
\hline I. Newly diagnosed diabetes patients & $\begin{array}{l}\text { Proportion of diabetes patients obtaining eye screening for diabetic retinopathy and } \\
\text { maculopathy within the prospective time period (I2 months from diagnosis) } \\
\text { 2. Frequency of diabetic eye screening }\end{array}$ \\
$\begin{array}{ll}\text { Proportion of diabetes patients obtaining eye screening for diabetic retinopathy and } \\
\text { maculopathy within the defined interval }\end{array}$ \\
$\begin{array}{ll}\text { Prevalence according to the stage of retinopathy and maculopathy } \\
\text { maculopathy }\end{array}$ & $\begin{array}{l}\text { Proportion of diabetes patients progressing to a more severe level of diabetic eye disease } \\
\text { Proportion of diabetes patients regressing to a milder stage of diabetic eye disease }\end{array}$ \\
4. Prevalence of blindness & Proportion of patients registered as blind
\end{tabular}

Abbreviation: DiaBase, Danish Registry of Diabetic Retinopathy.

- Previous eye surgery

- Best corrected visual acuity

- Screening method (slit lamp examination or retinal photography)

- Diabetic retinopathy and maculopathy grading according to Wilkinson et al ${ }^{12}$

- Quality of screening photograph

- Definition of next examination (screening, treatment)

- Interval to next screening visit.

The data on diabetes type and duration of disease are recorded in The Adult Diabetes Registry.

\section{Follow-up}

A DiaBase report containing calculations of the key indicators is published every year. At annual meetings, data issues, interregional variations, and definition of indicators are discussed among representatives from each region.

\section{Descriptive data analysis from DiaBase annual report 2014-2015}

\section{Patient classification}

DiaBase identifies patients with newly diagnosed maculopathy as "diabetic maculopathy, newly diagnosed". In case of treatment for diabetic eye disease, screening is temporarily discontinued. After completion of treatment, patients re-enter regular diabetic eye screening and are described as "resumed routine screening". ${ }^{9}$ Patients with treated diabetic maculopathy are recorded in the category "treated maculopathy, stable". If maculopathy recurs, requiring additional treatment, patients are classified as "treated maculopathy, recurrence". The same system applies to diabetic retinopathy. DiaBase classifies treated patients as "laser-treated proliferative diabetic retinopathy, stable". In case of relapse requiring additional laser treatment, patients are labeled "laser-treated proliferative diabetic retinopathy, recurrence".

\section{Frequency of eye screening}

Until 2013, this indicator measured the proportion of diabetes patients who received eye screening at least every 2 years. However, the interval for screening visits should be tailored to the severity of disease. ${ }^{4,5}$ To provide the basis for individualized eye screening intervals, the definition of this indicator was changed to measure the proportion of patients who were screened within the defined time interval (Table 2). This ultimately measures access to screening for diabetes patients. Neither hospital eye departments nor ophthalmologists in private practice met the standard for this variable (at least $90 \%$ of patients should obtain eye screening within the defined interval). As this is the first year, this indicator is calculated in its altered state, the amount of data collected is still insufficient to provide a proper analysis.

\section{Prevalence of diabetic retinopathy and maculopathy}

The nationwide prevalence of nonproliferative diabetic retinopathy is $18 \%$, with $47 \%$ of patients screened in hospitals and $14 \%$ by ophthalmologists in private practice (Table 3 ). Mild nonproliferative diabetic retinopathy alone contributes to $13 \%$, while $78 \%$ of diabetes patients do not have diabetic retinopathy. However, there are differences between patients screened in hospitals and by ophthalmologists in private practice. Eighty-six percent of patients screened by ophthalmologists in private practice display no retinopathy, with minor interregional variations. Only $53 \%$ of patients screened in hospitals have no diabetic retinopathy, with a wide interregional disparity. These numbers indicate that a higher proportion of patients with more severe diabetes are being treated in hospital departments compared to private ophthalmological practice.

In the Central Denmark Region, $11 \%$ of patients screened in hospitals have "proliferative diabetic retinopathy, newly diagnosed", a significantly higher number than in other regions of Denmark. There is less interregional difference if preproliferative patients are included in this category. Even 
Table 2 Screening within the planned interval

\begin{tabular}{|c|c|c|c|c|c|}
\hline \multicolumn{6}{|c|}{$\begin{array}{l}\text { Proportion of diabetes patients obtaining eye screening for diabetic retinopathy and maculopathy within the planned interval } \\
\text { (standard: at least } 90 \% \text { ) }\end{array}$} \\
\hline \multirow[t]{2}{*}{ Geographic area/health sector } & \multicolumn{3}{|c|}{ Current year: March 2014-February 2015} & \multicolumn{2}{|c|}{ Earlier years, \% } \\
\hline & $\begin{array}{l}\text { Numeratorl } \\
\text { denominator }\end{array}$ & Unknown, N (\%) & $\begin{array}{l}\text { Proportion } \\
(95 \% \mathrm{Cl})\end{array}$ & $\begin{array}{l}\text { Proportion, } \\
2013-2014\end{array}$ & $\begin{array}{l}\text { Proportion, } \\
2012-2013^{b}\end{array}$ \\
\hline Denmark & $22,962 / 35,440$ & $2,565(7)$ & $65(64-65)$ & 60 & 64 \\
\hline Hospital units, total & $8,493 / 16,002$ & $2,305(13)$ & $53(52-54)$ & 63 & 64 \\
\hline Capital Region of Denmark ${ }^{a}$ & $1,212 / 4,842$ & $2,065(30)$ & $25(24-26)$ & 31 & 42 \\
\hline Region Zealand & $\mid, 343 / I, 851$ & $42(2)$ & $73(70-75)$ & 69 & 62 \\
\hline Region of Southern Denmark & $2,473 / 3,711$ & $106(3)$ & $67(65-68)$ & 87 & 87 \\
\hline Central Denmark Region & $2,043 / 3,232$ & $88(3)$ & $63(62-65)$ & 64 & 62 \\
\hline North Denmark Region & $\mathrm{I}, 422 / 2,366$ & $4(<1)$ & $60(58-62)$ & 58 & 66 \\
\hline Ophthalmological practices, total & $14,469 / 19,438$ & $260(1)$ & $74(74-75)$ & 45 & \\
\hline Capital Region of Denmark & $2,205 / 3,175$ & $165(5)$ & $69(68-7 I)$ & 36 & \\
\hline Region Zealand & $454 / 708$ & $16(2)$ & $64(60-68)$ & 16 & \\
\hline Region of Southern Denmark & $8,400 / 10,326$ & $70(I)$ & $81(81-82)$ & 56 & \\
\hline Central Denmark Region & $2,915 / 4,124$ & $8(<1)$ & 71 (69-72) & 37 & \\
\hline North Denmark Region & $495 / 1,105$ & $\mathrm{I}(<\mathrm{I})$ & $45(42-48)$ & 19 & \\
\hline
\end{tabular}

Notes: Numerator: patients whose eye screening was performed within the defined interval $\pm \sim 33 \%$ of the defined interval (months to next eye screening): 3 months \pm I month, 6 months \pm 2 months, 12 months \pm 4 months, 18 months \pm 6 months, 24 months \pm 8 months, 48 months \pm 12 months; denominator: all screening visits were performed in the defined period, where an earlier visit had been recorded and a planned interval defined by the ophthalmologist; unknown: number of months to next screening visit not disclosed. aDifferent screening strategies with longer \pm tolerances compared with the other regions explain the low numbers. ${ }^{b}$ Data collection from patients screened in ophthalmological practice started in 2013 and is still being extended to cover all practices.

Abbreviation: $\mathrm{Cl}$, confidence interval.

Table 3 Prevalence of diabetic retinopathy (March 20I4-February 2015)

\begin{tabular}{|c|c|c|c|c|c|c|c|c|}
\hline \multirow{2}{*}{$\begin{array}{l}\text { Geographic region/health } \\
\text { sector }\end{array}$} & \multirow{2}{*}{$\begin{array}{l}\text { Patients } \\
\text { with known } \\
\text { retinopathy } \\
\text { status (n) }\end{array}$} & \multicolumn{7}{|c|}{ Retinopathy status } \\
\hline & & $\begin{array}{l}\text { None } \\
\text { (\%) }\end{array}$ & $\begin{array}{l}\text { Mild } \\
(\%)\end{array}$ & $\begin{array}{l}\text { Moderate } \\
(\%)\end{array}$ & $\begin{array}{l}\text { Preproliferative } \\
\text { (\%) }\end{array}$ & $\begin{array}{l}\text { Proliferative, } \\
\text { stable (\%) }\end{array}$ & $\begin{array}{l}\text { Proliferative, } \\
\text { new (\%) }\end{array}$ & $\begin{array}{l}\text { Proliferative, } \\
\text { recurrence (\%) }\end{array}$ \\
\hline Denmark & 77,968 & 78 & 13 & 4 & 1 & 1 & 3 & 0 \\
\hline Hospital units, total & 20,000 & 53 & 26 & 10 & 2 & 4 & 4 & 0 \\
\hline Capital Region of Denmark & 8,216 & 60 & 29 & 3 & 1 & 3 & 4 & 0 \\
\hline Region Zealand & 2,044 & 49 & 21 & $\mathrm{II}$ & 5 & 12 & 1 & 1 \\
\hline Region of Southern & 4,028 & 52 & 17 & 18 & 5 & 8 & 0 & 0 \\
\hline \multicolumn{9}{|l|}{ Denmark } \\
\hline Central Denmark Region & 3,276 & 36 & 40 & 13 & 1 & 0 & 11 & 0 \\
\hline North Denmark Region & 2,436 & 53 & 22 & 16 & 3 & 0 & 6 & 0 \\
\hline $\begin{array}{l}\text { Ophthalmological practices, } \\
\text { total }\end{array}$ & 57,968 & 86 & 9 & 2 & 0 & 0 & 2 & 0 \\
\hline Capital Region of Denmark & $\mathrm{II}, 245$ & 91 & 6 & 2 & 0 & 0 & 1 & 0 \\
\hline Region Zealand & 7,210 & 87 & 9 & 2 & 0 & 0 & 2 & 0 \\
\hline Region of Southern & 20,828 & 85 & 9 & 3 & 0 & 0 & 3 & 0 \\
\hline \multicolumn{9}{|l|}{ Denmark } \\
\hline Central Denmark Region & 12,205 & 84 & 11 & 2 & 0 & 0 & 3 & 0 \\
\hline North Denmark Region & 6,480 & 87 & 9 & 2 & 0 & 0 & 1 & 0 \\
\hline
\end{tabular}

though DiaBase clearly defines the criteria for classification of preproliferative versus proliferative diabetic retinopathy, regional traditions may play a role in differing interpretations. Sight-threatening subtypes (newly diagnosed and previously treated recurrent proliferative diabetic retinopathy) comprise $3 \%$ of patients. The number of patients with recurrence after treatment is very small. One percent of patients are recorded as "laser treated and stable".
Diabetic maculopathy is significantly more uncommon than diabetic retinopathy. The overall prevalence of patients without diabetic maculopathy is $97 \%$ in the registry (91\% screened in hospitals vs $98 \%$ screened by ophthalmologists in private practice). Only $2 \%$ of all patients have newly diagnosed diabetic maculopathy, and an equally small number of patients have stable maculopathy after treatment (Table 4). 
Table 4 Prevalence of diabetic maculopathy (March 2014-February 2015)

\begin{tabular}{|c|c|c|c|c|c|}
\hline \multirow[t]{2}{*}{ Geographic region/health sector } & \multirow{2}{*}{$\begin{array}{l}\text { Patients with known } \\
\text { maculopathy status (n) }\end{array}$} & \multicolumn{4}{|c|}{ Maculopathy status } \\
\hline & & None (\%) & Stable (\%) & New (\%) & Recurrence (\%) \\
\hline Denmark & 74,554 & 97 & 2 & 2 & 0 \\
\hline Hospital units, total & 19,267 & 91 & 3 & 6 & 0 \\
\hline Capital Region of Denmark & 7,777 & 91 & 3 & 6 & 0 \\
\hline Region Zealand & 1,824 & 77 & 11 & 12 & I \\
\hline Region of Southern Denmark & 3,959 & 94 & 3 & 3 & 0 \\
\hline Central Denmark Region & 3,292 & 90 & 0 & 10 & 0 \\
\hline North Denmark Region & 2,415 & 100 & 0 & 0 & 0 \\
\hline Ophthalmological practices, total & 55,287 & 98 & I & 0 & 0 \\
\hline Capital Region of Denmark & 10,742 & 99 & 1 & 0 & 0 \\
\hline Region Zealand & 6,957 & 98 & I & 0 & 0 \\
\hline Region of Southern Denmark & 19,762 & 98 & 1 & $\mathrm{I}$ & 0 \\
\hline Central Denmark Region & 11,622 & 98 & I & 0 & 0 \\
\hline North Denmark Region & 6,204 & 99 & I & 0 & 0 \\
\hline
\end{tabular}

Table 5 Progression of diabetic eye disease

\begin{tabular}{|c|c|c|c|c|c|}
\hline \multicolumn{6}{|c|}{ Proportion of diabetes patients progressing to a more severe level of diabetic eye disease } \\
\hline \multirow[t]{2}{*}{ Geographic area/health sector } & \multicolumn{3}{|c|}{ Current year: March 2014-February 2015} & \multicolumn{2}{|c|}{ Earlier years, \% } \\
\hline & $\begin{array}{l}\text { Numeratorl } \\
\text { denominator }\end{array}$ & Unknown, N (\%) & $\begin{array}{l}\text { Proportion } \\
(95 \% \mathrm{Cl})\end{array}$ & $\begin{array}{l}\text { Proportion, } \\
2013-2014\end{array}$ & $\begin{array}{l}\text { Proportion, } \\
2012-2013^{a}\end{array}$ \\
\hline Denmark & $2,905 / 28,912$ & $339(1)$ & $10(10-10)$ & 14 & 14 \\
\hline Hospital units, total & $2,106 / 13,668$ & $309(2)$ & $15(15-16)$ & 14 & 14 \\
\hline Capital Region of Denmark & $573 / 4,776$ & $284(6)$ & $12(11-13)$ & 11 & 12 \\
\hline Region Zealand & $262 / 1,446$ & $4(<1)$ & $18(16-20)$ & 15 & 13 \\
\hline Region of Southern Denmark & $472 / 3,143$ & $0(0)$ & $15(14-16)$ & 11 & 11 \\
\hline Central Denmark Region & $353 / 2,280$ & $2 I(I)$ & $15(14-17)$ & 16 & 16 \\
\hline North Denmark Region & $444 / 2,023$ & $0(0)$ & $22(20-24)$ & 17 & 17 \\
\hline Ophthalmological practices, total & $799 / 15,244$ & $30(<1)$ & $5(5-6)$ & 12 & \\
\hline Capital Region of Denmark & $|2| / 2,460$ & $20(1)$ & $5(4-6)$ & 9 & \\
\hline Region Zealand & $24 / 4 \mid 4$ & $6(1)$ & $6(4-9)$ & 10 & \\
\hline Region of Southern Denmark & $417 / 8,346$ & $2(<1)$ & $5(5-5)$ & 21 & \\
\hline Central Denmark Region & $202 / 3,383$ & $2(<1)$ & $6(5-7)$ & 10 & \\
\hline North Denmark Region & $35 / 64 I$ & $0(0)$ & $5(4-8)$ & 7 & \\
\hline
\end{tabular}

Notes: Numerator: patients whose poorest eye progressed to a more severe stage of diabetic eye disease since the last eye screening visit in the year before the annual report (higher number $=$ more severe stage of disease): I, none; 2 , mild nonproliferative; 3 , moderate nonproliferative; 4 , preproliferative; 5 , treated stable proliferative retinopathy/macular edema; 6 , active proliferative retinopathy or diabetic macular edema - treated or recurrence. Denominator: all patients whose poorest eye was not labeled as being in the most severe stage of eye disease previous to the year of the annual report. ${ }^{2}$ Data collection from patients screened in ophthalmological practice started in 2013 and is still being extended to cover all practices.

Abbreviation: $\mathrm{Cl}$, confidence interval.

\section{Progression/regression of diabetic retinopathy and maculopathy}

Diabetic retinal changes may progress as well as regress, essentially depending on medical treatment and diabetic control. The proportion of diabetes patients progressing to a more severe level of diabetic eye disease is a key outcome measurement for DiaBase (Table 5). This requires at least two eye screening visits with retinopathy and maculopathy grading. To calculate this indicator, patients with the poorest-seeing eye and in the most severe stage of disease at the first of the screening visits are excluded from the assessment. Furthermore, the proportion of diabetes patients regressing to a milder stage of diabetic eye disease is assessed (Table 6). This also requires at least two eye screening visits with retinopathy and maculopathy grading. To calculate this indicator, patients with the poorest-seeing eye and in the mildest stage of disease (none) at the first of the screening visits are excluded from the assessment.

In 2014-2015, 10\% of registered patients progressed to a more severe stage of disease nationwide. However, this figure is lower than that reported during 2013-2014 (14\%). ${ }^{9}$ Five percent of patients screened by ophthalmologists in private practice progress to a more severe disease compared to $15 \%$ of patients screened in hospitals. There is a wide interregional variation $(12 \%-22 \%)$ in the latter group. The proportion of patients regressing to a milder stage of disease has been analyzed for the first time in 2014-2015. 
Table 6 Regression of diabetic eye disease

\begin{tabular}{|c|c|c|c|c|c|}
\hline \multicolumn{6}{|c|}{ Proportion of diabetes patients regressing to a milder stage of diabetic eye disease } \\
\hline \multirow[t]{2}{*}{ Geographic area/health sector } & \multicolumn{3}{|c|}{ Current year: March 2014-February 2015} & \multicolumn{2}{|c|}{ Earlier years, \% } \\
\hline & $\begin{array}{l}\text { Numeratorl } \\
\text { denominator }\end{array}$ & $\begin{array}{l}\text { Unknown, } \\
\text { N (\%) }\end{array}$ & $\begin{array}{l}\text { Proportion } \\
(95 \% \mathrm{CI})\end{array}$ & $\begin{array}{l}\text { Proportion, } \\
2013-2014\end{array}$ & $\begin{array}{l}\text { Proportion, } \\
2012-2013^{a}\end{array}$ \\
\hline Denmark & $\mathrm{I}, 558 / 7,759$ & $339(4)$ & $20(|9-2|)$ & 20 & 18 \\
\hline Hospital units, total & $1,040 / 5,622$ & $309(5)$ & $18(17-20)$ & 19 & 18 \\
\hline Capital Region of Denmark & $364 / 1,611$ & $284(15)$ & $23(21-25)$ & 19 & 18 \\
\hline Region Zealand & $148 / 742$ & $4(I)$ & $20(17-23)$ & 18 & 12 \\
\hline Region of Southern Denmark & $205 / I, \mid 149$ & $0(0)$ & $18(16-20)$ & 15 & 13 \\
\hline Central Denmark Region & $\mid 74 / 1,474$ & $21(1)$ & $12(10-14)$ & 15 & 14 \\
\hline North Denmark Region & $149 / 646$ & $0(0)$ & $23(20-27)$ & 32 & 37 \\
\hline Ophthalmological practices, total & $518 / 2,137$ & $30(1)$ & $24(22-26)$ & 44 & \\
\hline Capital Region of Denmark & $65 / 230$ & $20(8)$ & $28(23-35)$ & 46 & \\
\hline Region Zealand & $28 / 111$ & $6(5)$ & $25(17-34)$ & 27 & \\
\hline Region of Southern Denmark & $2|4 / I| 47$, & $2(<1)$ & $19(|6-2|)$ & 47 & \\
\hline Central Denmark Region & $|4| / 528$ & $2(<1)$ & $27(23-31)$ & 42 & \\
\hline North Denmark Region & $70 / 121$ & $0(0)$ & $58(49-67)$ & 60 & \\
\hline
\end{tabular}

Notes: Numerator: patients whose poorest eye regressed to a milder stage of diabetic eye disease since the last eye screening visit in the previous year; denominator: all patients whose poorest eye was not labeled as being in the mildest stage of disease (none) previous to the current year (2014-2015). ${ }^{\mathrm{a} D a t a}$ collection from patients screened in ophthalmological practice started in 2013 and is still being extended to cover all practices.

Abbreviation: $\mathrm{Cl}$, confidence interval.

Eighteen percent of patients screened in hospitals regress to a milder stage of disease (interregional variation between $12 \%$ and $23 \%$ ). Twenty-four percent of patients screened by ophthalmologists in private practice regressed to a milder stage of disease. Nonetheless, the percentage of these patients is significantly higher in the North Denmark region (58\%) than in the other regions, where percentages vary between $19 \%$ and $28 \%$. This difference may be based on variations in grading due to region-specific circumstances.

\section{Administrative issues and funding}

DiaBase was established by N Andersen in collaboration with The Danish Ophthalmological Society and the Organization of Danish Ophthalmologists in Private Practice, ${ }^{13}$ based on the status screening for diabetic retinopathy in Denmark. ${ }^{14}$ The registry is led by a steering committee of medical retina specialists representing the five regions of Denmark, the Chairman of the Danish Ophthalmological Society, and the Chairman of the Organization of Danish Ophthalmologists in Private Practice.

Initially, the register was partly funded by Hovedstadens Sygehusfællesskab (Association of Hospitals in the Capital Region of Denmark). DiaBase is funded and operated by The Danish Clinical Registries (RKKP), which is financed and owned by the five Danish regions.

\section{Conclusion}

The systematic collection of data from diabetic eye screening in Denmark is still in the development process. Data analysis from DiaBase's latest annual report (2014-2015) ${ }^{11}$ reveals a decrease in the prevalence of diabetic retinopathy from $26 \%$ to $22 \%$ compared to the previous report (2013-2014), whereas the number of patients diagnosed with diabetes has increased between 1996 and 2012. ${ }^{10}$ Additionally, the proportion of patients with regression (20\%) is greater than the proportion of patients with progression $(10 \%)$ of diabetic retinopathy.

The DiaBase is a useful tool to observe the quality of screening, prevalence, and progression/regression of diabetic eye disease. Thus, it contributes to ensure a high quality of care for diabetes patients in Denmark. Reducing the overall morbidity and mortality associated with diabetes by preventing complications may help to relieve the large economic burden of the disease.

\section{Acknowledgments}

This paper was funded by the Program for Clinical Research Infrastructure (PROCRIN) established by the Lundbeck Foundation and the Novo Nordisk Foundation. We would like to thank the staff of all hospital departments and all ophthalmologists in private practice for their valued contribution in providing data on patients with diabetes in Denmark.

\section{Disclosure}

KC Schielke is an advisory board member of Bayer. J Grauslund is an advisory board member of Allergan, Bayer, and Novartis Healthcare. The authors report no other conflicts of interest in this work. 


\section{References}

1. Klein R, Klein BE, Moss SE, Davis MD, DeMets DL. The Wisconsin epidemiologic study of diabetic retinopathy II. Prevalence and risk of diabetic retinopathy when age at diagnosis is less than 30 years. Arch Ophthalmol. 1984;102(4):520-526.

2. Klein R, Klein BE, Moss SE, Davis MD, DeMets DL. The Wisconsin epidemiologic study of diabetic retinopathy III. Prevalence and risk of diabetic retinopathy when age at diagnosis is 30 or more years. Arch Ophthalmol. 1984;102(4):527-532.

3. The Royal College of Ophthalmologists. London: Diabetic Retinopathy Guidelines 2012 [updated July 2013]. Available from: https://www. rcophth.ac.uk/standards-publications-research/clinical-guidelines/. Accessed August 1, 2015.

4. Aspelund T, Thornórisdóttir O, Olafsdottir E, et al. Individual risk assessment and information technology to optimise screening frequency for diabetic retinopathy. Diabetologia. 2011;54(10):2525-2532.

5. Dansk Oftalmologisk Selskab: Kliniske retningslinier for diabetisk øjensygdom - retningslinier for screening, forebyggelse og behandling [Clinical guidelines for diabetic eye disease - Guidelines for screening, prevention and treatment]. 2009. Available from: http://www. dansk-oftalmologisk-selskab.dk/arkiver/486. Accessed August 1, 2015. Danish.

6. Brown MM, Brown GC, Sharma S, Busbee B. Quality of life associated with visual loss: a time trade-off utility analysis comparison with medical health states. Ophthalmology. 2003;110(6):1076-1081.

7. Grauslund J, Green A, Sjolie AK. Blindness in a 25-year follow-up of a population-based cohort of Danish type 1 diabetic patients. Ophthalmology. 2009;116(11):2170-2174.
8. Jeppesen P, Bek T. The occurrence and causes of registered blindness in diabetes patients in Århus County, Denmark. Acta Ophthalmol Scand. 2004;82(5):526-530.

9. Kompetencecenter Vest: Den landsdækkende kliniske kvalitetsdatabase for screening af diabetisk retinopati og maculopati (DiaBase), Version1, November 2013 [Center for Competence West: The national clinical quality database for screening of diabetic retinopathy and maculopathy (DiaBase)]. Available from: http://www.kcks-vest.dk/ kliniske-kvalitetsdatabaser/diabase/. Accessed August 1, 2015. Danish.

10. Statens Seruminstitut: Tal på diabetes 1996-2012 [Serum State Institute: Numbers on diabetes 1996-2012]. Available from: http://www.ssi. $\mathrm{dk} /$ Sundhedsdataogit/Sundhedsvaesenet $\% 20 \mathrm{i} \% 20 \mathrm{tal} /$ Specifikke $\% 20$ omraader/Diabetes.aspx. Accessed August 1, 2015. Danish.

11. Dansk Diabetes Database: National årsrapport 2014/2015. Kommenteret version 1.1.[Danish Diabetes Database: National Annual Report 2014/2015. Version 1.1. with comments]. Available from: https://www. sundhed.dk/content/cms/87/4687_kom_\%C3\%A5rsrapport_diabetes_2014_15_27082015_endelig.pdf. Accessed August 1, 2015. Danish.

12. Wilkinson CP, Ferris FL 3rd, Klein RE, et al; Global Diabetic Retinopathy Project Group. Proposed international clinical diabetic retinopathy and diabetic macular edema disease severity scales. Ophthalmology. 2003;110(9):1677-1682.

13. Andersen N. DiaBase - en national klinisk kvalitetsdatabase for systematisk screening for diabetisk retinopati [DiaBase - a national clinical quality database for systematic screening of diabetic retinopathy. Danish Society of Ophthalmology]. Ugeskr Laeger. 2005;167:1400. Danish.

14. Hansen AB, Andersen MVN. Screening for diabetic retinopathy in Denmark: the current status. Acta Ophthalmologica Scand. 2004;82(6):673-678.
Clinical Epidemiology

\section{Publish your work in this journal}

Clinical Epidemiology is an international, peer-reviewed, open access, online journal focusing on disease and drug epidemiology, identification of risk factors and screening procedures to develop optimal preventative initiatives and programs. Specific topics include: diagnosis, prognosis, treatment, screening, prevention, risk factor modification,

\section{Dovepress}

systematic reviews, risk and safety of medical interventions, epidemiology and biostatistical methods, and evaluation of guidelines, translational medicine, health policies and economic evaluations. The manuscript management system is completely online and includes a very quick and fair peer-review system, which is all easy to use. 